\title{
Renal tubular acidosis with hyperchloremic acidosis: harmless with a sting?
}

\author{
Patrick M. Honore*, Rita Jacobs, Inne Hendrickx, Elisabeth De Waele, Viola Van Gorp and Herbert D. Spapen \\ See related research by Brunner et al., http://www.ccforum.com/content/19/1/148
}

Brunner et al. [1] showed a higher than previously described prevalence of renal tubular acidosis (RTA) in critically ill patients with hyperchloremic metabolic acidosis (HMA). They elegantly demonstrated that this condition often remains unrecognized owing to the simultaneous presence of metabolic alkalosis, mainly attributed to low plasma albumin levels, and was not associated with increased morbidity or mortality. HMA was thought to result from altered renal chloride handling as seen in RTA and was considered a nonharmful physiological response.

In contrast with the study of Brunner et al., HMA is most often exogenously induced by too liberal infusion of chloride-containing intravenous fluids for hydration and resuscitation purposes [2]. HMA indeed has no proven impact on ICU and hospital mortality but may precipitate acute kidney injury. It could be assumed that a combination of HMA and RTA only guarantees a relatively stable but fragile acid-base equilibrium with preserved renal function provided the external chloride load remains limited. Excess or overzealous administration of chloride may well precipitate or exacerbate acute kidney injury in these patients. Conversely, early identification of the HMA/RTA combination strongly pleads against a liberal chloride infusion policy and may eventually offer kidney protection!

\section{Abbreviations}

HMA: Hyperchloremic metabolic acidosis; RTA: Renal tubular acidosis.

\section{Competing interests}

The authors declare that they have no competing interests.

Published online: 28 August 2015

\section{References}

1. Brunner R, Drolz A, Scherzer TM, Staufer K, Fuhrmann V, Zauner C, et al. Renal tubular acidosis is highly prevalent in critically ill patients. Crit Care. 2015;19:148.

2. Yunos NM, Bellomo R, Hegarty C, Story D, Ho L, Bailey M. Association between a chloride-liberal vs chloride-restrictive intravenous fluid administration strategy and kidney injury in critically ill adults. JAMA. 2012;308:1566-72.

\footnotetext{
* Correspondence: Patrick.Honore@az.vub.ac.be

ICU Department, UZ Brussel_-VUB University, 101 Laarbeeklaan, 1090 Jette, Brussels, Belgium
}

\section{Biomed Central}

(c) 2015 Honore et al. Open Access This article is distributed under the terms of the Creative Commons Attribution 4.0 International License (http://creativecommons.org/licenses/by/4.0), which permits unrestricted use, distribution, and reproduction in any medium, provided you give appropriate credit to the original author(s) and the source, provide a link to the Creative Commons license, and indicate if changes were made. The Creative Commons Public Domain Dedication waiver (http://creativecommons.org/publicdomain/zero/1.0/) applies to the data made available in this article, unless otherwise stated. 